\title{
From inflammation to gastric cancer: Role of Helicobacter pylori (Review)
}

\author{
XIAO-YING ZHANG ${ }^{1}$, PEI-YING ZHANG ${ }^{2}$ and MOURAD A.M. ABOUL-SOUD ${ }^{3}$ \\ ${ }^{1}$ Nanjing University of Chinese Medicine, Information Institute, Nanjing; ${ }^{2}$ Department of Cardiology, \\ Xuzhou Central Hospital, The Affiliated Xuzhou Hospital of Medical College of Southeast University, Xuzhou, \\ Jiangsu 221009, P.R. China; ${ }^{3}$ Chair of Medical and Molecular Genetics Research, Department of Clinical Laboratory \\ Sciences, College of Applied Medical Sciences, King Saud University, Riyadh 11433, Kingdom of Saudi Arabia
}

Received July 7, 2016; Accepted December 8, 2016

DOI: $10.3892 / \mathrm{ol} .2016 .5506$

\begin{abstract}
Gastric cancer is a multifactorial disease and a leading cause of mortality and the risk factors for this include environmental factors and factors that influence host-pathogen interaction and complex interplay between these factors. Gastric adenocarcinomas are of two types, namely intestinal and diffuse type, and Helicobacter pylori (H.pylori) infection has been suspected of being causally linked to the initiation of chronic active gastritis, which leads to adenocarcinoma of the intestinal type. Even though most individuals with $H$. pylori infection do not show any clinical symptoms, long-term infection leads to inflammation of gastric epithelium and approximately $10 \%$ of infected patients develop peptic ulcers and $1-3 \%$ of patients develop gastric adenocarcinoma. Among the several mechanisms involved in tumorigenesis, CagA and peptidoglycan of $H$. pylori, which enter the infected gastric epithelial cells play an important role by triggering oncogenic pathways. Inflammation induced by $H$. pylori in gastric epithelium, which involves the cyclooxygenase-2/prostaglandin E2 pathway and IL-1 $\beta$, is also an important factor that triggers chronic active gastritis and adenocarcinoma. $H$. pylori infection induced oxidative stress and dysregulated E-cadherin/ $\beta$-catenin/p120 interactions and function also play a critical role in tumorigenesis. Environmental and dietary factors, in particular salt intake, are known to modify the pathogenesis induced by $H$. pylori. Gastric cancer induced
\end{abstract}

Correspondence to: Dr Pei-Ying Zhang, Department of Cardiology, Xuzhou Central Hospital, The Affiliated Xuzhou Hospital of Medical College of Southeast University, 199 South Jiefang Road, Xuzhou, Jiangsu 221009, P.R. China

E-mail: zpying58@126.com

Professor Mourad A.M. Aboul-Soud, Chair of Medical and Molecular Genetics Research, Department of Clinical Laboratory Sciences, College of Applied Medical Sciences, King Saud University, P.O. Box 10219, Riyadh 11433, Kingdom of Saudi Arabia

E-mail: maboulsoud@ksu.edu.sa

Key words: inflammation, gastric cancer, Helicobater pylori by $H$. pylori appears to involve several mechanisms, making this mode of tumorigenesis a highly complicated process. Nevertheless, there are many events in this tumorigenesis that remain to be clarified and investigated.

\section{Contents}

1. Introduction

2. Events leading to gastric carcinogenesis following H. pylori infection

3. Inflammatory response to $H$. pylori infection

4. Oxidative stress induced by H. pylori

5. H.pylori and E-cadherin

6. Environmental factors and H.pylori-mediated gastric carcinogenesis

7. Conclusion

\section{Introduction}

Gastric cancer is a leading cause of cancer-related mortality worldwide, with nearly 1 million new cases and approximately 750,000 mortalities annually (1). Gastric cancer is a multifactorial disease and the risk factors for this include environmental factors and factors that influence hostpathogen interaction and complex interplay between these factors. Gastric cancer occurrence is more predominant in developing countries in Eastern Europe, South America, and Asia, accounting for approximately two thirds of all cases globally, with China representing approximately $42 \%$ of all new cases (2). Development of gastric cancer likely originates with the onset of chronic active gastritis and follows with atrophic gastritis, intestinal metaplasia, and dysplasia, eventually leading to gastric cancer (3). Besides environmental, diet and genetic factors, gastric cancer is closely associated with Helicobacter pylori (H. pylori) infection (4) and related host gene polymorphisms (5). Gastric adenocarcinomas constitute $90-95 \%$ of gastric cancers and are of two types, intestinal and diffuse type. Although there is no known precursor lesion for the development of diffuse type of gastric cancers, $H$. pylori infection has been suspected of being causally linked to the 
initiation of chronic active gastritis, which leads to adenocarcinoma (6). Infection of $H$. pylori is one of the thoroughly studied risk factors of gastric cancer.

After its identification in 1984, H. pylori was classified as a type I carcinogen and epidemiological studies indicated that $H$. pylori is the most common etiological agent for cancers that are related to infection $(7,8)$. H. pylori is a gram-negative bacterial pathogen and is colonized in gastric epithelium despite the harsh acidic environment, because of its ability to conduct urease-mediated breakdown of urea to ammonia to release ammonia and neutralize its surrounding environment (9). Even though most individuals with $H$.pylori infection do not exhibit any clinical symptoms, long-term infection potentially leads to inflammation of gastric epithelium and approximately $10 \%$ of infected patients develop peptic ulcers and 1-3\% subjects develop gastric adenocarcinoma $(10,11)$.

In this review, we address the molecular basis by which $H$.pylori acts as a carcinogen, the potential factors that enhance the risk from $H$. pylori and the accumulating epidemiological evidence for $H$. pylori infection and its effect on gastric cancer incidence.

\section{Events leading to gastric carcinogenesis following H. pylori infection}

H. pylori infection of gastric epithelium leads to the development of intestinal-type adenocarcinoma with the primary event being the transition from normal mucosa to chronic superficial gastritis. Subsequently, atrophic gastritis ensues followed by intestinal metaplasia, leading to dysplasia and adenocarcinoma (Fig. 1) (12). Men are twice as susceptible as women to the intestinal type of gastric adenocarcinoma (13). Notably, the location of infection and formation of gastritis influences the outcomes. Thus, corpus-predominant gastritis leads to gastric cancer, probably because of lower acid secretion, whereas, infection of the gastric antrum, which increases acid production predisposes individuals to duodenal ulcer, actually decreases the risk of gastric cancer (14).

cag pathogenicity island and CagA. Several virulence factors present in $H$. pylori that are influenced by its genetic heterogeneity, are critical in the pathogenesis of gastric cancer. CagA, which is present in the DNA insertion element, cag pathogenicity island ( $c a g \mathrm{PAI}$ ), was found to be important in carcinogenesis and thus, only $H$. pylori strains that contain cagPAI element enhance the risk of atrophic gastritis and gastric cancer, even though all strains of this bacterium can cause gastritis $(15,16)$. H. pylori CagA is a 120 to $140-\mathrm{kDa}$ protein, which translocates into host cells following attachment of the bacteria to the cell. Inside the host cell, CagA is phosphorylated by Abl and Src kinases, on tyrosine residue at four distinct glutamate-proline-isoleucine -tyrosine-alanine (EPIYA) motifs present at the C-terminal region of the protein, leading to morphological changes in the cell, including increased cell migration $(17,18)$. The number and phosphorylation status of these EPIYA motifs is a determinant and indicator of risk for gastric cancer (19). Tyr-phospho-CagA activates tyrosine phosphatase (SHP-2) in the host cell, leading to sustained activation of ERK1/2, Crk adaptor, and C-terminal Src kinase (20). Interaction between phosphor-CagA and SHP leads to cell elongation by different mechanisms (21). Even non-phosphorylated CagA has pathogenic effects by causing aberrant activation of $\beta$-catenin, disruption of apical-junctional complexes, and a loss of cellular polarity (22). Additionally, non-phosphorylated CagA targets E-cadherin, the hepatocyte growth factor receptor c-Met, phospholipase C- $\gamma$, the adaptor protein Grb2, and other components that lead to proinflammatory and mitogenic responses, disruption of cell-cell junctions, and loss of cell polarity (Fig. 1) (23). Preclinical studies confirmed a role for CagA in the pathogenesis of gastric cancer, by demonstrating that transgenic mice expressing CagA show gastric epithelial cell proliferation and carcinoma, in a CagA phosphorylation-dependent manner (24).

Peptidoglycan. Along with CagA, H. pylori peptidoglycan can also be delivered into host cells and peptidoglycan binds with NodI (25), which triggers the NF- $\mathrm{BB}$ dependent pro-inflammatory pathway and interleukin (IL)-8, an inflammatory cytokine, secretion. Peptidoglycan is also shown to activate the PI3K-Akt pathway leading to cell proliferation, migration and prevention of apoptosis (26).

Other virulence factors present in $H$. pylori include VacA and outer membrane proteins, which are associated with ulceration as well as gastric cancer $(27,28)$.

\section{Inflammatory response to $H$. pylori infection}

COX-2/PGE2 pathway. Inflammation of gastric epithelium is known to be associated with the development of gastric cancer (29). There are several mechanisms by which inflammation may promote cancer development and the induction of the cyclooxygenase-2/prostaglandin E2 (COX-2/PGE2) pathway and activation of NF- $\mathrm{KB}$ and Stat 3 appear to be major pathways (Fig. 2) (30). Besides these, innate immune responses through the TLR/MyD88 adapter signaling also play a role in tumorigenesis $(31,32)$. In fact, it has been shown that almost all the gastric tumors show an induction of COX-2 expression (33) and H. pylori infection is known to lead to COX-2 induction (34). Inflammation in combination with oncogenic activation, promotes tumorigenesis and also Wnt signaling activation (Fig. 2) with the accumulation of $\beta$-catenin, which facilitate tumor growth and this altered signaling has been observed in over 50\% of gastric cancers (35). PGE2 signaling, through the EP4 receptor, is known to induce the expansion of $\mathrm{CD} 33^{+} \mathrm{CD}_{4} 4^{+}$cancer stem cells in intestinal tumors through the activation of PI3K and MAPK signaling (36), which potentially aggravates tumor growth.

Infection of $H$. pylori induces inflammation through Cag A injection into host cells followed by the activation of SHP and TLRs leading to chronic active gastritis and eventually gastric cancer. However, the expression pattern of inflammation markers is not always comparable between gastritis and gastric cancer. Thus, IL-8 and IL-11 expression is predominantly induced in gastric cancer, whereas in gastritis mostly TNF- $\alpha$ expression is increased. It has been suggested that once tumor growth starts, tumor cells also contribute to the inflammation of local microenvironment through different pathways, known as 'tumor-elicited inflammation', which is different from infection-induced inflammation, thereby resulting in different cytokine profiles from H. pylori infection-induced gastritis (29). Nevertheless, gastritis and 


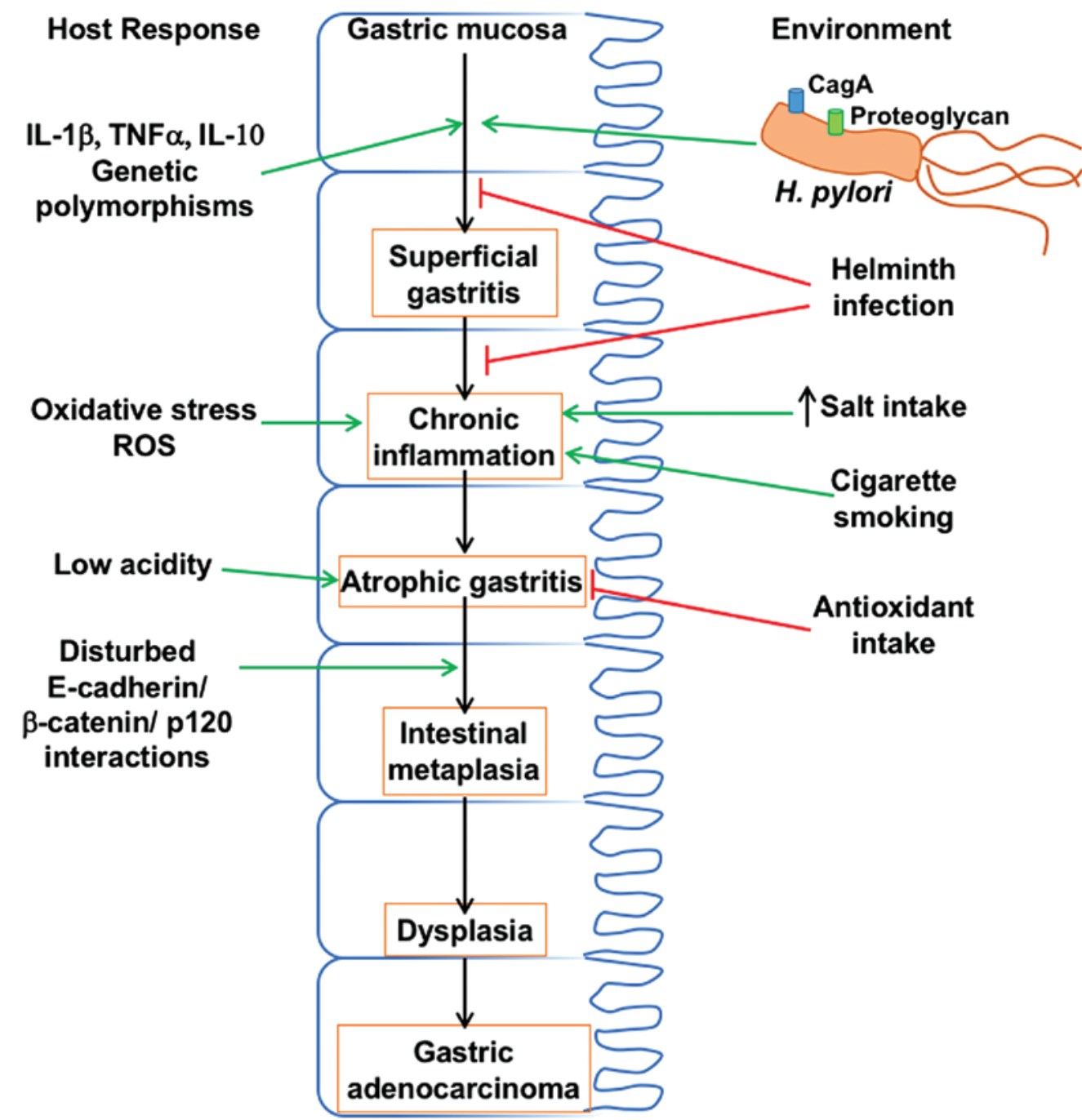

Figure 1. Interaction between host responses, changes in gastric mucosa and environment during gastric carcinogenesis induced by Helicobacter pylori (H. pylori). A combination of several host responses, bacterial pathogen-mediated events, and environmental factors contribute to the precancerous cascade that culminates in gastric adenocarcinoma.

gastric cancer demonstrate common increases in inflammatory cytokines CXCL1, CXCL2, CXCL5, CCL3, CCL4, and TLR2 (Fig. 2) (29). Inasmuch as these cytokines are effective in causing immune suppression, the 'infection-associated' and 'tumor- elicited' inflammation appears to promote and accelerate gastric tumorigenesis by activating the COX-2/PGE2 pathway and subsequent induction of tumor-promoting cytokines.

$I L-1 \beta$. Another important cytokine, IL-1 $\beta$ is known to play a role in a variety of cellular activities such as inflammatory response and acid secretion by gastric epithelium (37). Disturbances in the regulation of IL-1 $\beta$ are observed in several cancer types and in particular, in IL-1 $\beta$ gene polymorphisms including IL-1 $\beta-31(\mathrm{~T}>\mathrm{C})$ and IL-1 $\beta-511(\mathrm{C}>\mathrm{T})$ which are closely related to gastric cancer (Fig. 1) $(38,39)$. Of note, it has been shown that IL-1 $\beta-511$ T polymorphism is present in all the Mozambican subjects with intestinal metaplasia (40). This polymorphism is also associated with the prevalence of dysplasia (41), indicating that the IL-1 $\beta \mathrm{T}$ alleles are related to premalignant gastric lesions. Apparently, the same polymorphism of IL-1 $\beta$ is involved in the intestinal type of gastric cancers, which are triggered by $H$. pylori infection and not diffusive type (42). IL-1 $\beta$ gene polymorphisms also increase the production of IL-1 $\beta$, which suppresses gastric acid secretion, and is related to the grade of gastric atrophy in patients with $H$. pylori infection (43). Additionally, H. pylori infection leads to elevated secretion of IL-1 $\beta$ and reduction in acid secretion (44). It has been suggested that a combination of IL-1 $\beta-511 \mathrm{~T} / \mathrm{T}$ polymorphism and $H$. pylori infection aggravates the development of gastric tumor more than either of these agents alone (45). Thus, infection of $H$. pylori promotes the expression of IL-1 $\beta$, which leads to gastric carcinogenesis through its actions on both inflammatory and epithelial cells (46). Even though the precise molecular basis of these actions is not clear, it seems that hypochlorhydria and atrophic gastritis induced by IL- $1 \beta$ polymorphisms, which depends on $H$. pylori infection are critical in gastric cancer development (47).

\section{Oxidative stress induced by $H$. pylori}

A primary factor that is important in the events that lead to the progression of the inflammation-to-carcinoma is oxidative DNA damage induced by $H$. pylori infection (48), which is 


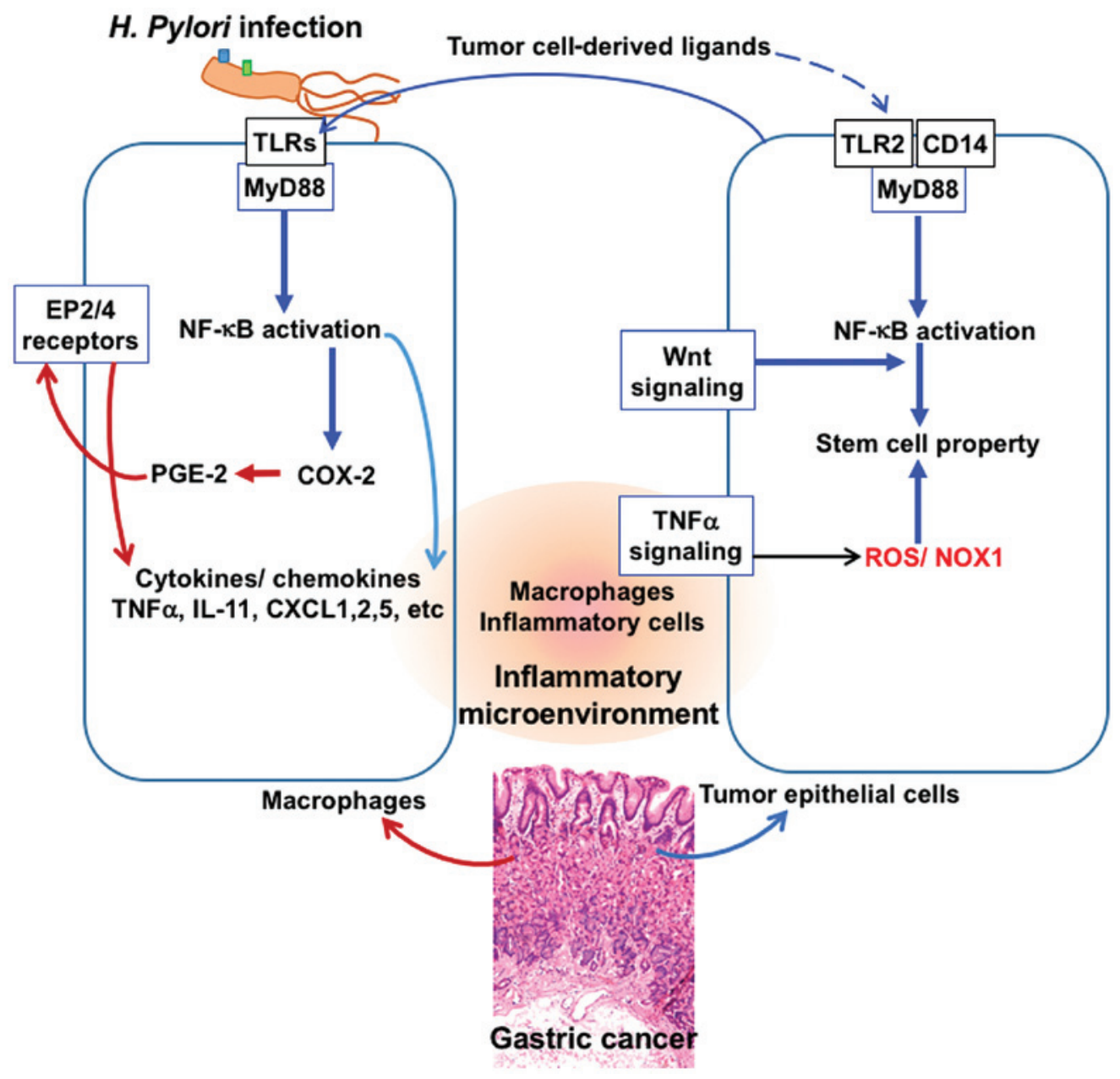

Figure 2. Tumor inflammatory microenvironment: Interplay of factors derived from $H$. pylori and tumor cells. A crosstalk between tumor cell-derived inflammatory factors and macrophage-derived factors during infection of Helicobacter pylori (H. pylori) results in aggravation of the inflammatory microenvironment and the tumor cells acquiring stem cell property and progression of tumor in gastric epithelium. Signaling through the TLR/MyD88/NF- $\mathrm{kB}$ pathways to activate cyclooxygenase-2 (COX-2) and production of prostaglandin E2 (PGE-2), release of cytokines such as TNF- $\alpha$ and production of ROS, in macrophages and in tumor cells facilitate this tumor inflammatory environment.

probably due to infiltrating neutrophils, and also direct effects of $H$. pylori (49). Production of reactive oxygen species in the $H$. pylori-infected gastric epithelium is linked to the presence of cagPAI and contribute to the oxidative stress response in gastric epithelial cells (50). It is well known that $H$. pylori infection causes elevated level of polyamines, in particular spermine and this is associated with an induction of spermine oxidase (51). Action of spermine oxidase on spermine leads to the production of elevated levels of hydrogen peroxide, which is a powerful oxidizing agent and also contributes to the production of free radicals such as hydroxyl radical (52). Besides, H. pylori also activates macrophages which show a significant upregulation of spermine oxidase, contributing to oxidative stress and damage to the gastric epithelial cells (53). Besides, altered polyamine metabolism and overexpression of arginase enzyme in the infected gastric epithelium leads to lowered NO production and increased production of spermine and hydrogen peroxide.

\section{H.pylori and E-cadherin}

E-cadherin, which is an adhesion molecule in epithelial tissues that is important in maintaining proper cellular architecture, is regulated by the binding of p120 to the cadherin juxtamembrane domain (54). Furthermore, the cytoplasmic domain of E-cadherin interacts with $\beta$-catenin and p120, which, in turn, interact with the cytoskeletal component actin. It has been documented that there is a loss of E-cadherin function in gastric cancer, and in fact promoter methylation of E-cadherin gene is induced by $H$. pylori infection, leading to reduction in E-cadherin expression (55). Following $H$. pylori infection, the translocated $\mathrm{CagA}$ in the gastric epithelial cells binds with E-cadherin, resulting in the dissociation of the E-cadherin- $\beta$-catenin complex and accumulation of $\beta$-catenin in cytoplasm and nucleus, where it transactivates $\beta$-catenin-dependent genes involved in carcinogenesis $(23,56)$. Along with the downregulation of E-cadherin, a decreased expression or aberrant subcellular localization of p120, from membrane to the cytosol or nucleus, is commonly seen in gastric cancer (57). In the cytoplasm, p120 interacts with Rho GTPases and promotes motility and metastasis (58). Aberrant localization of p120 to the nucleus in gastric epithelia infected with $H$. pylori has been reported and p120 in nucleus can relieve transcriptional repression of the mmp-7 gene, which is involved in gastric tumorigenesis, leading to its enhanced expression (59). 


\section{Environmental factors and $H$. pylori-mediated gastric carcinogenesis}

Gastric adenocarcinoma is strongly influenced by dietary salt intake, with high salt intake aggravating tumorigenesis (60). Epidemiological studies indicated that high salt intake increases the prevalence of $H$. pylori infection (61) and the incidence of gastric adenocarcinoma in infected patients (62). Experimental studies indicated that a high-salt diet and $H$. pylori infection exert synergistic effects on the development of premalignant lesions or gastric cancer (63), probably by elevating the production of inflammatory cytokines IL-1, IL-6 and TNF- $\alpha$ (64). However, the precise molecular events that underlie this synergistic effect on cancer development are not known. It has been suggested that high salt increases the expression of $\mathrm{CagA}$, the potential carcinogen in H. pylori (65), which may be the reason for the observed synergy between $H$. pylori and salt for gastric cancer induction (Fig. 1).

In addition to salt, other factors that influence $H$. pylori infection-associated gastric cancer include helminth infections and dietary antioxidant intake, both of which seem to have a negative effect on the ability of $H$. pylori to induce gastritis and thus cancer. On the other hand, cigarette smoking is a potential risk factor for enhancing the tumorigenesis induced by $H$. pylori infection (21).

\section{Conclusion}

Intestinal type gastric adenocarcinomas are known to be causally linked to $H$. pylori infection, which leads to the initiation of chronic active gastritis, and adenocarcinoma. Even though most individuals with $H$. pylori infection do not show any clinical symptoms, 1-3\% people with long-term infection develop gastric adenocarcinoma. Of the several mechanisms of the tumorigenesis induced by $H$. pylori, CagA and peptidoglycan of $H$. pylori, inflammation, oxidative stress and dysregulated E-cadherin/ $\beta$-catenin/p120 interactions play an important role. Environmental and dietary factors, in particular salt intake and cigarette smoking are known to aggravate $H$. pylori-induced carcinogenesis. Thus, $H$. pylori infection appears to invoke multi-thronged mechanisms, to induce gastric adenocarcinoma. Nevertheless, many events in this tumorigenic process remain to be clarified and investigated.

\section{References}

1. Ferro A, Peleteiro B, Malvezzi M, Bosetti C, Bertuccio P, Levi F, Negri E, La Vecchia C, Lunet N: Worldwide trends in gastric cancer mortality (1980-2011), with predictions to 2015, and incidence by subtype. Eur J Cancer 50: 1330-1344, 2014.

2. Jemal A, Bray F, Center MM, Ferlay J, Ward E and Forman D: Global cancer statistics. CA Cancer J Clin 61: 69-90, 2011.

3. Correa P: Human gastric carcinogenesis: a multistep and multifactorial process - first American cancer society award lecture on cancer epidemiology and prevention. Cancer Res 52: 6735-6740, 1992.

4. Herrera V and Parsonnet J: Helicobacter pylori and gastric adenocarcinoma. Clin Microbiol Infect 15: 971-976, 2009.

5. He C, Tu H, Sun L, Xu Q, Li P, Gong Y, Dong N and Yuan Y: Helicobacter pylori-related host gene polymorphisms associated with susceptibility of gastric carcinogenesis: a two-stage case-control study in Chinese. Carcinogenesis 34: 1450-1457, 2013.
6. Souza RF and Spechler SJ: Concepts in the prevention of adenocarcinoma of the distal esophagus and proximal stomach. CA Cancer J Clin 55: 334-351, 2005.

7. Marshall BJ and Warren JR: Unidentified curved bacilli in the stomach of patients with gastritis and peptic ulceration. Lancet 1: 1311-1315, 1984

8. Parkin DM, Bray F, Ferlay J and Pisani P: Global cancer statistics, 2002. CA Cancer J Clin 55: 74-108, 2005.

9. Weeks DL, Eskandari S, Scott DR and Sachs G: A H $\mathrm{H}^{+}$-gated urea channel: the link between Helicobacter pylori urease and gastric colonization. Science 287: 482-485, 2000.

10. Peek RM Jr and Blaser MJ: Helicobacter pylori and gastrointestinal tract adenocarcinomas. Nat Rev Cancer 2: 28-37, 2002.

11. Peek RM Jr and Crabtree JE: Helicobacter infection and gastric neoplasia. J Pathol 208: 233-248, 2006.

12. Sipponen P and Marshall BJ: Gastritis and gastric cancer. Western countries. Gastroenterol Clin North Am 29: 579-592, 2000.

13. Correa P and Houghton J: Carcinogenesis of Helicobacter pylori. Gastroenterology 133: 659-672, 2007.

14. Atherton JC: The pathogenesis of Helicobacter pylori-induced gastro-duodenal diseases. Annu Rev Pathol 1: 63-96, 2006.

15. Shimoyama T, Fukuda S, Tanaka M, Mikami T, Munakata A and Crabtree JE: CagA seropositivity associated with development of gastric cancer in a Japanese population. J Clin Pathol 51: 225-228, 1998 .

16. Torres J, Pérez-Pérez GI, Leal-Herrera Y and Muñoz O: Infection with $\mathrm{CagA}^{+}$Helicobacter pylori strains as a possible predictor of risk in the development of gastric adenocarcinoma in Mexico. Int J Cancer 78: 298-300, 1998.

17. Stein M, Bagnoli F, Halenbeck R, Rappuoli R, Fantl WJ and Covacci A: c-Src/Lyn kinases activate Helicobacter pylori CagA through tyrosine phosphorylation of the EPIYA motifs. Mol Microbiol 43: 971-980, 2002.

18. Segal ED, Cha J, Lo J, Falkow S and Tompkins LS: Altered states: involvement of phosphorylated CagA in the induction of host cellular growth changes by Helicobacter pylori. Proc Natl Acad Sci USA 96: 14559-14564, 1999.

19. Basso D, Zambon CF, Letley DP, Stranges A, Marchet A, Rhead JL, Schiavon S, Guariso G, Ceroti M, Nitti D, et al: Clinical relevance of Helicobacter pylori cag A and vacA gene polymorphisms. Gastroenterology 135: 91-99, 2008.

20. Higashi H, Tsutsumi R, Muto S, Sugiyama T, Azuma T, Asaka M and Hatakeyama M: SHP-2 tyrosine phosphatase as an intracellular target of Helicobacter pylori CagA protein. Science 295: 683-686, 2002.

21. Wroblewski LE, Peek RM Jr and Wilson KT: Helicobacter pylori and gastric cancer: factors that modulate disease risk. Clin Microbiol Rev 23: 713-739, 2010.

22. Bagnoli F, Buti L, Tompkins L, Covacci A and Amieva MR: Helicobacter pylori CagA induces a transition from polarized to invasive phenotypes in MDCK cells. Proc Natl Acad Sci USA 102: 16339-16344, 2005.

23. Murata-Kamiya N, Kurashima Y, Teishikata Y, Yamahashi Y, Saito Y, Higashi H, Aburatani H, Akiyama T, Peek RM Jr, Azuma $\mathrm{T}$, et al: Helicobacter pylori CagA interacts with E-cadherin and deregulates the beta-catenin signal that promotes intestinal transdifferentiation in gastric epithelial cells. Oncogene 26: 4617-4626, 2007.

24. Ohnishi N, Yuasa H, Tanaka S, Sawa H, Miura M, Matsui A, Higashi H, Musashi M, Iwabuchi K, Suzuki M, et al: Transgenic expression of Helicobacter pylori CagA induces gastrointestinal and hematopoietic neoplasms in mouse. Proc Natl Acad Sci USA 105: 1003-1008, 2008

25. Viala J, Chaput C, Boneca IG, Cardona A, Girardin SE, Moran AP, Athman R, Mémet S, Huerre MR, Coyle AJ, et al: Nod1 responds to peptidoglycan delivered by the Helicobacter pylori cag pathogenicity island. Nat Immunol 5: 1166-1174, 2004.

26. Nagy TA, Frey MR, Yan F, Israel DA, Polk DB and Peek RM Jr: Helicobacter pylori regulates cellular migration and apoptosis by activation of phosphatidylinositol 3-kinase signaling. J Infect Dis 199: 641-651, 2009.

27. Miehlke S, Kirsch C, Agha-Amiri K, Günther T, Lehn N, Malfertheiner P, Stolte M, Ehninger G and Bayerdörffer E: The Helicobacter pylori vacA s1, $\mathrm{m} 1$ genotype and cag A is associated with gastric carcinoma in Germany. Int $\mathrm{J}$ Cancer 87: 322-327, 2000

28. Dossumbekova A, Prinz C, Gerhard M, Brenner L, Backert S, Kusters JG, Schmid RM and Rad R: Helicobacter pylori outer membrane proteins and gastric inflammation. Gut 55: 1360-1361, 2006 
29. Echizen K, Hirose O, Maeda Y and Oshima M: Inflammation in gastric cancer: interplay of the COX-2/prostaglandin E2 and Toll-like receptor/MyD88 pathways. Cancer Sci 107: 391-397, 2016.

30. Grivennikov SI, Greten FR and Karin M: Immunity, inflammation, and cancer. Cell 140: 883-899, 2010.

31. Pradere JP, Dapito DH and Schwabe RF: The yin and yang of toll-like receptors in cancer. Oncogene 33: 3485-3495, 2014.

32. Maeda Y, Echizen K, Oshima H, Yu L, Sakulsak N, Hirose O, Yamada Y, Taniguchi T, Jenkins BJ, Saya H, et al: Myeloid differentiation factor 88 signaling in bone marrow-derived cells promotes gastric tumorigenesis by generation of inflammatory microenvironment. Cancer Prev Res (Phila) 9: 253-263, 2016.

33. Saukkonen K, Rintahaka J, Sivula A, Buskens CJ, Van Rees BP, Rio MC, Haglund C, Van Lanschot JJ, Offerhaus GJ and Ristimaki A: Cyclooxygenase-2 and gastric carcinogenesis. APMIS 111: 915-925, 2003.

34. Sung JJ, Leung WK, Go MY, To KF, Cheng AS, Ng EK and Chan FK: Cyclooxygenase-2 expression in Helicobacter pylori-associated premalignant and malignant gastric lesions. Am J Pathol 157: 729-735, 2000

35. Oshima H, Matsunaga A, Fujimura T, Tsukamoto T, Taketo MM and Oshima M: Carcinogenesis in mouse stomach by simultaneous activation of the Wnt signaling and prostaglandin E2 pathway. Gastroenterology 131: 1086-1095, 2006.

36. Wang D, Fu L, Sun H, Guo L and DuBois RN: Prostaglandin E2 promotes colorectal cancer stem cell expansion and metastasis in mice. Gastroenterology 149: 1884-1895, 2015.

37. Jayaraman P, Sada-Ovalle I, Nishimura T, Anderson AC, Kuchroo VK, Remold HG and Behar SM: IL-1 $\beta$ promotes antimicrobial immunity in macrophages by regulating TNFR signaling and caspase-3 activation. J Immunol 190: 4196-4204, 2013.

38. Kumar S, Kumar A and Dixit VK: Evidences showing association of interleukin-1B polymorphisms with increased risk of gastric cancer in an Indian population. Biochem Biophys Res Commun 387: 456-460, 2009.

39. Garza-González E, Bosques-Padilla FJ, El-Omar E, Hold G, Tijerina-Menchaca R, Maldonado-Garza HJ and Pérez-Pérez GI: Role of the polymorphic IL-1B, IL-1RN and TNF-A genes in distal gastric cancer in Mexico. Int J Cancer 114 237-241, 2005

40. Peleteiro B, Lunet N, Carrilho C, Durães C, Machado JC, La Vecchia C and Barros H: Association between cytokine gene polymorphisms and gastric precancerous lesions: systematic review and meta-analysis. Cancer Epidemiol Biomarkers Prev 19: 762-776, 2010.

41. Marcos-Pinto R, Dinis-Ribeiro M, Carneiro F, Wen X, Lopes C, Figueiredo C, Machado JC, Ferreira RM, Reis CA, Canedo P, et al: First-degree relatives of early-onset gastric cancer patients show a high risk for gastric cancer: phenotype and genotype profile. Virchows Arch 463: 391-399, 2013.

42. Kamangar F, Cheng C, Abnet CC and Rabkin CS: Interleukin-1B polymorphisms and gastric cancer risk - a meta-analysis. Cancer Epidemiol Biomarkers Prev 15: 1920-1928, 2006.

43. Waghray M, Zavros Y, Saqui-Salces M, El-Zaatari M, Alamelumangapuram CB, Todisco A, Eaton KA and Merchant JL: Interleukin-1beta promotes gastric atrophy through suppression of Sonic Hedgehog. Gastroenterology 138: 562-572, 2010.

44. Wang M, Furuta T, Takashima M, Futami H, Shirai N, Hanai H and Kaneko E: Relation between interleukin-1beta messenger RNA in gastric fundic mucosa and gastric juice $\mathrm{pH}$ in patients infected with Helicobacter pylori. J Gastroenterol 34 (Suppl 11) 10-17, 1999

45. Zeng ZR, Hu PJ, Hu S, Pang RP, Chen MH, Ng M and Sung JJ Association of interleukin 1B gene polymorphism and gastric cancers in high and low prevalence regions in China. Gut 52: $1684-1689,2003$

46. Shigematsu Y, Niwa T, Rehnberg E, Toyoda T, Yoshida S, Mori A, Wakabayashi M, Iwakura Y, Ichinose M, Kim YJ, et al Interleukin-1 $\beta$ induced by Helicobacter pylori infection enhances mouse gastric carcinogenesis. Cancer Lett 340: 141-147, 2013.

47. Furuta T, El-Omar EM, Xiao F, Shirai N, Takashima M and Sugimura H: Interleukin lbeta polymorphisms increase risk of hypochlorhydria and atrophic gastritis and reduce risk of duodenal ulcer recurrence in Japan. Gastroenterology 123 : 92-105, 2002.
48. Farinati F, Cardin R, Degan P, Rugge M, Mario FD, Bonvicini P and Naccarato R: Oxidative DNA damage accumulation in gastric carcinogenesis. Gut 42: 351-356, 1998.

49. Obst B, Wagner S, Sewing KF and Beil W: Helicobacter pylori causes DNA damage in gastric epithelial cells. Carcinogenesis 21 $1111-1115,2000$

50. Ding SZ, Minohara Y, Fan XJ, Wang J, Reyes VE, Patel J, Dirden-Kramer B, Boldogh I, Ernst PB and Crowe SE: Helicobacter pylori infection induces oxidative stress and programmed cell death in human gastric epithelial cells. Infect Immun 75: 4030-4039, 2007.

51. Cheng Y, Chaturvedi R, Asim M, Bussière FI, Scholz A, Xu H, Casero RA Jr and Wilson KT: Helicobacter pylori-induced macrophage apoptosis requires activation of ornithine decarboxylase by c-Myc. J Biol Chem 280: 22492-22496, 2005.

52. Xu H, Chaturvedi R, Cheng Y, Bussiere FI, Asim M, Yao MD, Potosky D, Meltzer SJ, Rhee JG, Kim SS, et al: Spermine oxidation induced by Helicobacter pylori results in apoptosis and DNA damage: implications for gastric carcinogenesis. Cancer Res 64: 8521-8525, 2004

53. Chaturvedi R, Cheng Y, Asim M, Bussière FI, Xu H, Gobert AP, Hacker A, Casero RA Jr and Wilson KT: Induction of polyamine oxidase 1 by Helicobacter pylori causes macrophage apoptosis by hydrogen peroxide release and mitochondrial membrane depolarization. J Biol Chem 279: 40161-40173, 2004

54. JoTY, Jeon TY, Chae KH, Kim DH, Sim MS, Park DY and Suh KS: RImmunohistochemical evaluation of E-cadherin/catenin (alpha-, beta-, gamma-catenin and p120CTN) complex expression in early gastric cancer. Cancer Res Treat 35: 16-24, 2003.

55. Perri F, Cotugno R, Piepoli A, Merla A, Quitadamo M, Gentile A, Pilotto A, Annese V and Andriulli A: Aberrant DNA methylation in non-neoplastic gastric mucosa of $H$. pylori infected patients and effect of eradication. Am J Gastroenterol 102: 1361-1371, 2007.

56. Oliveira MJ, Costa AM, Costa AC, Ferreira RM, Sampaio P, Machado JC, Seruca R, Mareel M and Figueiredo C: CagA associates with c-Met, E-cadherin, and p120-catenin in a multiproteic complex that suppresses Helicobacter pylori-induced cell-invasive phenotype. J Infect Dis 200: 745-755, 2009.

57. Jawhari AU, Noda M,Pignatelli M and Farthing M: Up-regulated cytoplasmic expression, with reduced membranous distribution, of the src substrate p120(ctn) in gastric carcinoma. J Pathol 189: $180-185,1999$.

58. Noren NK, Liu BP, Burridge K and Kreft B: p120 catenin regulates the actin cytoskeleton via Rho family GTPases. J Cell Biol 150: 567-580, 2000.

59. Ogden SR, Wroblewski LE, Weydig C, Romero-Gallo J, O'Brien DP, Israel DA, Krishna US, Fingleton B, Reynolds AB, Wessler S, et al: p120 and Kaiso regulate Helicobacter pyloriinduced expression of matrix metalloproteinase-7. Mol Biol Cell 19: 4110-4121, 2008

60. Tsugane S: Salt, salted food intake, and risk of gastric cancer: epidemiologic evidence. Cancer Sci 96: 1-6, 2005.

61. Beevers DG, Lip GY and Blann AD: Salt intake and Helicobacter pylori infection. J Hypertens 22: 1475-1477, 2004.

62. Shikata K, Kiyohara Y, Kubo M, Yonemoto K, Ninomiya T, Shirota T, Tanizaki Y, Doi Y, Tanaka K, Oishi Y, et al: A prospective study of dietary salt intake and gastric cancer incidence in a defined Japanese population: the Hisayama study. Int J Cancer 119: 196-201, 2006.

63. Gamboa-Dominguez A, Ubbelohde T, Saqui-Salces M, Romano-Mazzoti L, Cervantes M, Domínguez-Fonseca C, de la Luz Estreber M and Ruíz-Palacios GM: Salt and stress synergize $H$. pylori-induced gastric lesions, cell proliferation, and p21 expression in Mongolian gerbils. Dig Dis Sci 52: 1517-1526, 2007.

64. Sun J, Aoki K, Zheng JX, Su BZ, Ouyang XH and Misumi J: Effect of $\mathrm{NaCl}$ and Helicobacter pylori vacuolating cytotoxin on cytokine expression and viability. World J Gastroenterol 12: 2174-2180, 2006

65. Gancz H, Jones KR and Merrell DS: Sodium chloride affects Helicobacter pylori growth and gene expression. J Bacteriol 190: 4100-4105, 2008. 